\title{
Morfologia de plântulas das espécies de Rhynchosia (Leguminosae, Papilionoideae) de Roraima, Brasil
}

\author{
Rodrigo Schütz Rodrigues ${ }^{1,3}$, Ana Paula Moreira Hirt² e Andréia Silva Flores ${ }^{2}$
}

Recebido em 10/11/2011. Aceito em 7/05/2012

\begin{abstract}
RESUMO
(Morfologia de plântulas das espécies de Rhynchosia (Leguminosae, Papilionoideae) de Roraima, Brasil). Este trabalho tem como objetivos descrever, ilustrar e comparar a morfologia de plântulas das quatro espécies de Rhynchosia (Leguminosae, Papilionoideae) ocorrentes no estado de Roraima, Brasil. Todas as espécies estudadas, $R$. phaseoloides (SW.) DC., R. melanocarpa Grear, R. minima (L.) DC., e R. schomburgkii Benth. apresentam plântulas cripto-hipógeo-armazenadoras, eofilos do primeiro nó 1-foliolados, opostos e com estípulas duplas e livres entre si. Os resultados mostram que a diversidade morfológica encontrada nas plântulas das espécies estudadas permite identificá-las em nível específico. As espécies podem ser distintas entre si pela morfologia da lâmina e comprimento das estípulas do primeiro nó eofilar, bem como pelo número de folíolos e forma e venação das estípulas dos eofilos subseqüentes. Além disso, o trabalho discute a variação morfológica nas plântulas de Rhynchosia e esclarece informações discordantes na literatura sobre plântulas de R. minima e R. phaseoloides.
\end{abstract}

Palavras-chave: Fabaceae, Phaseoleae, desenvolvimento pós-seminal, planta juvenil

\begin{abstract}
(Seedling morphology of Rhynchosia species (Leguminosae, Papilionoideae) from Roraima, Brazil). This paper aims to describe, illustrate and compare the seedling morphology of the four species of Rhynchosia (Leguminosae, Papilionoideae) that occur in Roraima, Brazil. The studied species, $R$. phaseoloides (SW.) DC., R. melanocarpa Grear, $R$. minima (L.) DC., and R. schomburgkii Benth., possess crypto-hypogeal-reserve seedlings, eophylls at the first node that are 1-foliolate and opposite, and double and free stipules. The results show that morphological diversity found among seedlings of the studied species can be used to identify them at the specific level. Rhynchosia species are distinguishable from each other mainly by blade morphology and stipule length at the first eophyll node, as well as by the number of leaflets, shape and venation of the stipules of subsequent eophylls. This work also discusses the morphological variation found in Rhynchosia, and elucidates disparate data in the literature on seedlings of R. minima and R. phaseoloides.
\end{abstract}

Key words: Fabaceae, Phaseoleae, post-seminal development, sapling

\section{Introdução}

A fase de plântula é um estádio crítico no ciclo de vida das espermatófitas (Leck et al. 2008). A habilidade das plântulas para sobreviver ao período de alta mortalidade que decorre entre a dispersão das sementes e o estabelecimento da planta jovem é um importante fator para a posterior distribuição dos indivíduos adultos (Garwood 2009).

O interesse sobre a morfologia de plântulas de Leguminosae é remoto, como atestam trabalhos de De Candolle
(1825) e Lubbock (1892). Revisões apresentadas mais recentemente (Duke \& Polhill 1981; Vogel 1980; Garwood 2009) e diversos outros trabalhos têm revelado que a morfologia de plântulas pode fornecer vários caracteres com significado taxonômico (e.g. Nozzolillo 1977; 1985; Lima 1990; Nemoto \& Ohashi 1993; López et al. 1998; Oliveira 2001; Rodrigues \& Tozzi 2007a,b) ou filogenético em Leguminosae (Rodrigues \& Tozzi 2007c; 2008). Entretanto, ainda existem lacunas no conhecimento de vários grupos, pois espécimes no estádio de plântula ainda são pouco representados nos herbários (Garwood 2009).

\footnotetext{
${ }^{1}$ Universidade Federal de Roraima, Centro de Estudos da Biodiversidade, Boa Vista, RR, Brasil

${ }^{2}$ Museu Integrado de Roraima, Herbário, Boa Vista, RR, Brasil

${ }_{3}^{3}$ Autor para correspondência: rodschutz@gmail.com
} 
Para Phaseoleae (subfamília Papilionoideae), Baudet (1974) apresentou uma revisão da morfologia de plântulas envolvendo 109 espécies de 25 gêneros da tribo, incluindo Rhynchosia Lour., que é um gênero pantropical com cerca 230 espécies (Schrire 2005). Rhynchosia possui 55 espécies no Novo Mundo, das quais 26 são ocorrentes na América do Sul (Schrire 2005). Dados sobre plântulas ainda são escassos em Rhynchosia, existindo informações na literatura apenas para oito espécies (Lubbock 1892; Baudet 1974, Silcock 1980, Sanches \& Válio 2002; Garwood 2009; CCC-CCR 2011). Para espécies neotropicais, existem dados e ilustrações somente para R. calycosa Hemsl. e R. erythrinoides Schltdl. et Cham., ambas cripto-hipógeas (Garwood 2009). Para outras duas espécies ocorrentes no Novo Mundo, informações sobre plântulas são contraditórias na literatura: R. phaseoloides (SW.) DC., cuja germinação é referida como hipógea (Baudet 1974) ou faneroepígea (Sanches \& Válio 2002) e R. minima (L.) DC., para a qual existe breve informação que menciona plântulas de espécimes da Austrália como hipógeas (Silcock 1980) ou faneroepígeas (CCC-CCR 2011).

Garwood (2009) destacou a importância de floras regionais de plântulas como forma de suprir informações para estudos ecológicos e taxonômicos. Em Roraima, foram encontradas quatro espécies de Rhynchosia: $R$. phaseoloides, $R$. melanocarpa Grear, R. minima, e R. schomburgkii Benth., todas ocorrendo preferencialmente em áreas savânicas do Estado (Hirt \& Flores 2012). Rhynchosia schomburgkii apresenta a distribuição mais restrita dentre estas quatro espécies, ocorrendo somente no Norte da América do Sul, na Venezuela, Guiana, Brasil (Roraima) e disjuntamente no Oeste da Colômbia (Grear 1978). As demais espécies apresentam distribuição mais ampla, ao longo da América do Sul (R. melanocarpa), com extensão ao Caribe e América Central (R. phaseoloides) ou mesmo pantropical (R. minima) (Grear 1978).

Este trabalho tem como objetivo ampliar o conhecimento sobre a morfologia de plântulas de Rhynchosia, pela descrição, ilustração e comparação das plântulas das quatro espécies ocorrentes em Roraima, investigando a relevância dos atributos de morfologia de plântulas para a identificação destes táxons e o esclarecimento das informações discordantes sobre plântulas de R. minima e R. phaseoloides.

\section{Material e métodos}

Plântulas das espécies de Rhynchosia foram obtidas a partir de sementes coletadas em Roraima, Brasil. Para cada espécie, é referido o material testemunha da origem das sementes (exemplar adulto), seguido dos respectivos testemunhas de plântula, todos tombados no Herbário MIRR (Thiers 2012).

Rhynchosia phaseoloides - Exemplar adulto: BRASIL.

Roraima: Amajari, Serra do Tepequém, área da RPPN do SESC Tepequém, 15/X/2008, Rodrigues \& Serafim 2128 (MIRR); plântulas: Flores \& Rodrigues 2470; Flores \& Rodrigues 2474; Flores \& Rodrigues 2475 (MIRR).
Rhynchosia melanocarpa - Exemplar adulto: BRASIL. Roraima: Boa Vista, Cauamé, 14/V/2009, Hirt et al. 04 (MIRR); plântulas: Flores \& Rodrigues 2473, Flores \& Rodrigues 2477 (MIRR).

Rhynchosia minima - Exemplar adulto: BRASIL. Roraima: Boa Vista, Bosque dos papagaios, 24/II/2009, Flores et al. 2221 (MIRR); plântulas: Flores \& Rodrigues 2471; Flores \& Rodrigues 2480 (MIRR).

Rhynchosia schomburgkii - Exemplar adulto: BRASIL. Roraima: Bonfim, 10/VIII/2009, Hirt et al. 11 (MIRR); plântulas: Flores \& Rodrigues 2472; Flores \& Rodrigues 2476; Flores \& Rodrigues 2478; Flores \& Rodrigues 2479 (MIRR).

Para cada espécie, sementes foram escarificadas mecanicamente e germinadas em caixas tipo gerbox, sob uma camada de algodão recoberta por outra de papel de filtro, levemente umedecido com água destilada, à temperatura ambiente. Para acompanhar o desenvolvimento das plântulas, após a emissão da raiz primária, estas foram repicadas para tubos plásticos, com mistura em partes iguais de terra vegetal e areia e mantidas sob condições de casa de vegetação no Museu Integrado de Roraima. O termo plântula foi considerado no sentido amplo, ou seja, a fase transcorrida entre a germinação da semente até o aparecimento do primeiro metafilo (Parra 1984). Entretanto, para padronizar as descrições e permitir comparações entre diferentes táxons, dados qualitativos e quantitativos foram tomados somente até o completo desenvolvimento do terceiro eofilo, de acordo com Rodrigues \& Tozzi (2008). Foram medidas pelo menos 10 plântulas para cada espécie. Descrições foram baseadas principalmente em espécimes vivos ou em materiais prensados. A terminologia morfológica foi baseada em Vogel (1980), Rodrigues \& Tozzi (2008) e Garwood (2009). Os grupos morfológicos de plântulas foram classificados conforme Garwood (2009), que emprega dicotomicamente três caracteres de cotilédones (emergência, posição e função) para reconhecer cinco tipos morfológicos de plântulas (siglas originais em inglês): PEF (fanero-epígeo-foliáceo), PER (fanero-epígeo-armazenador), PHR (fanero-hipógeo-armazenador), CER (cripto-epígeo-armazenador) e CHR (cripto-hipógeo-armazenador). Observações noturnas foram feitas para detectar a ocorrência de movimentos nictinásticos em folíolos. Fotografias foram tomadas com uma câmera Nikon D90, enquanto que as análises morfológicas e algumas ilustrações foram feitas com auxílio de microscópio estereoscópico Nikon SMZ-800 com câmera clara. Os eofilos do primeiro, segundo e terceiro nós eofilares são abreviados como E1, E2 e E3 respectivamente.

\section{Resultados}

As espécies de Rhynchosia estudadas apresentaram plântulas com germinação cripto-hipógeo-armazenadora (CHR), já que os cotilédones são armazenadores, não emergentes (Fig. 1-2), brancos e não fotossintetizantes. 
O desenvolvimento das plântulas das quatro espécies estudadas é semelhante até a produção do E1, começando quando a raiz primária (Fig. 1A) e hipocótilo emergem da semente. O hipocótilo é curto e, desta forma, os cotilédones permanecem, durante o desenvolvimento da plântula, junto ao nível do solo. Posteriormente, tornam-se visíveis os pecíolos cotiledonares (Fig. 1B, 2G) e o epicótilo começa a se alongar (Fig. 1C). Cerca de 20-25 dias após a germinação, o epicótilo atinge o seu comprimento máximo e um par de E1 se alonga, até atingir sua completa expansão em cerca de 30-35 dias (Fig. 1D).

Em todas as espécies analisadas, a raiz primária é castanho-clara, não tuberizada e as raízes laterais podem ser moderadamente presentes a abundantes. Catafilos estão ausentes e as gemas axilares podem ser inconspícuas ou com até $0,5 \mathrm{~mm}$ compr. As estípulas do E1 são duplas e livres entre si (Fig. 2O), enquanto que nos demais eofilos, a partir de E2, elas são simples. Estipelas são ausentes em todos os táxons até o E3. Com relação à pubescência, os tricomas encontrados nas plântulas das espécies estudadas podem ser de três tipos: a) simples, eretos, canescentes e 0,25-0,5 mm compr.; b) glandulares, eretos, pedunculados, canescentes e 0,25-0,5 mm compr. e c) glandulares, sésseis, amarelos. Tricomas simples e glandulares sésseis foram encontrados nos epicótilos e lâminas foliolares em todas as quatro espécies estudadas. Entretanto, tricomas glandulares pedunculados foram encontrados somente em R. melanocarpa e R. schomburgkii. A pubescência das estípulas, pecíolos e, quando presentes, das raques foliares é semelhante à do epicótilo de cada espécie. Com relação aos eofilos, E1 são opostos e os subsequentes, alternos (Fig. 1D, 2A-F, 2H). Os pecíolos e, quando presentes, as raques foliares são canaliculados. As lâminas dos eofilos são inteiras (Fig. 2I-L), com venação broquidódroma. Quando 3-foliolados, os folíolos laterais dos E2 e E3 são opostos e nitidamente menores que os folíolos terminais (Fig. 2A-E). Com relação à nictinastia, as espécies estudadas apresentam folíolos com nictinastia descendente, ou seja, voltam-se para baixo e expõem sua face adaxial (Fig. 2M-N).

Descrição das plântulas das espécies de Rhynchosia de Roraima

1. Rhynchosia phaseoloides (Figs. 2A-B, I, M, O) - Plântula CHR. Hipocótilo 1-1,5 x 1,5 mm, cilíndrico, branco, glabro. Epicótilo 34-58 x 1,2-1,5 mm, cilíndrico, verdeclaro, densamente curto pubescente, com tricomas simples e tricomas glandulares sésseis. Entrenó 1 7-12 mm compr., entrenó 2 6,7-8,5 mm compr. Estípulas do E1 2-3,3 x 0,5-0,6 mm, linear-lanceoladas, nos demais eofilos 1,2-2 x 0,5-0,7 mm, triangulares, 3-4-nervadas; folíolos com ambas as faces esparsamente curto-pubescentes, com tricomas simples, a face abaxial também com tricomas glandulares sésseis. E1 1-foliolados, pecíolo 7-20 mm compr.; lâmina 20-34 x 17-24 mm, oval a triangular, ápice acuminado, base truncada; E2 3-foliolados, pecíolo 15-22 mm compr., raque 6-8 mm compr.; lâmina dos folíolos laterais 1623 x 8-13 mm, oval, ápice acuminado, base arredondada a truncada; lâmina dos folíolos terminais 23-32 x 18-26 mm, oval, ápice acuminado, base truncada; E3 3-foliolados, pecíolo 14-22 $\mathrm{mm}$ compr., raque 5-7 mm compr.; lâmina dos folíolos laterais 11-16 x 7-10 mm, oval, ápice acuminado, base arredondada a truncada; lâmina dos folíolos terminais $21-31 \mathrm{x}$ 19-25 mm, oval a triangular, ápice acuminado, base arredondada a truncada.

2. Rhynchosia melanocarpa (Fig. 2C-D, J) - Plântula CHR. Hipocótilo 1-1,5 x 1,5 mm, cilíndrico, creme, glabro. Epicótilo 41-45 x $1 \mathrm{~mm}$, cilíndrico, verde-claro, moderadamente curto pubescente, com tricomas simples e glandulares pedunculados, juntamente com tricomas glandulares sésseis. Entrenó 1 12-16 mm compr., entrenó 2 11-14 mm compr. Estípulas do E1 2-3 x 0,3-0,5 mm, linear-lanceoladas, nos demais eofilos $1,8-3 \times 0,4-0,5 \mathrm{~mm}$, linear-lanceoladas, 1-nervadas; folíolos com ambas as faces moderadamente curto-pubescentes com tricomas simples, a face abaxial também com tricomas glandulares sésseis. E1 1-foliolados, pecíolo 9-15 mm compr.; lâmina 17-21 x 18-24 mm, oval a largamente transversamente oval, ápice arredondado, apiculado, base lobada; E2 3-foliolados, pecíolo $15-20 \mathrm{~mm}$ compr., raque 3-5 $\mathrm{mm}$ compr.; lâmina dos folíolos laterais 13-17 x 7-10 mm, oval, ápice acuminado, base arredondada; lâmina dos folíolos terminais $26-27 \times 22-23 \mathrm{~mm}$, largamente transversamente oval, ápice acuminado, base cuneada a arredondada; E3 3-foliolados, pecíolo 14-18 mm compr., raque 4-5 mm compr.; lâmina dos folíolos laterais 16-17 x 9-10 mm, oval, ápice acuminado, base arredondada; lâmina dos folíolos terminais 29 × 22-24 mm, largamente transversamente oval, ápice acuminado, base cuneada a arredondada.

3. Rhynchosia minima (Fig. 2E, K) - Plântula CHR. Hipocótilo 1,5 x 1,5 mm, cilíndrico, creme, glabro. Epicótilo 36-45 x 0,8-1 mm, cilíndrico, verde-claro, moderadamente curto pubescente, com tricomas simples e glandulares sésseis. Entrenó 1 13-20 mm compr., entrenó 2 11-20 mm compr. Estípulas do E1 $1-1,3 \times 0,3-0,5 \mathrm{~mm}$, linear-lanceoladas, nos demais eofilos 1-1,5 x 0,4-0,5 mm, linear-lanceoladas, 1-nervadas; folíolos com face adaxial moderadamente curtopubescente, com tricomas simples e glandulares sésseis e face abaxial esparsamente curto-pubescente, com tricomas simples e glandulares sésseis. E1 1-foliolados, pecíolo 7-12 mm compr.; lâmina 13-17 x 10-13 mm, oval, ápice arredondado, base lobada; E2 3-foliolados, pecíolo 8-10 mm compr., raque 3-4 mm compr.; lâmina dos folíolos laterais 6-7 x 4-5 mm, oval, ápice agudo, base arredondada; lâmina dos folíolos terminais 10-14 x 8-12 mm, rômbica, ápice agudo, base arredondada; E3 3-foliolados, pecíolo 9-10 mm compr., raque 3-4 mm compr.; lâmina dos folíolos laterais 5-7 x 4-5 mm, oval, 


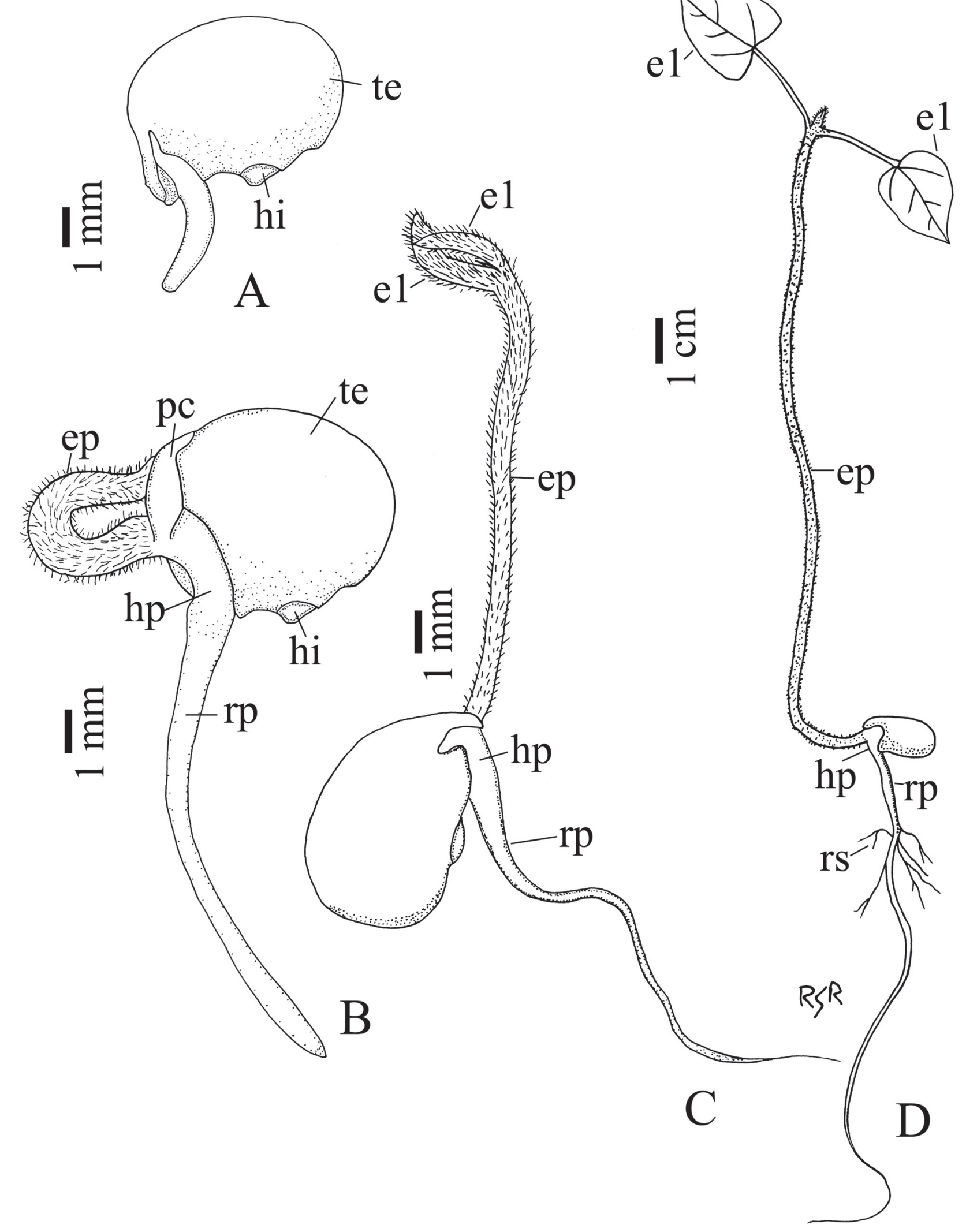

Figura 1. Desenvolvimento da plântula de Rhynchosia schomburgkii (Leguminosae, Papilionoideae). A. com 2 dias. B. com 7 dias. C. com 15 dias. D. com 25 dias.

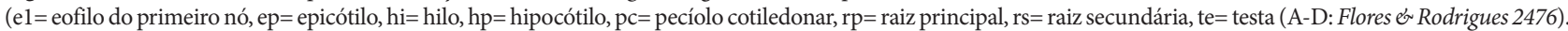


ápice agudo, base arredondada; lâmina dos folíolos terminais 12-14 x 10-12 mm, rômbica a largamente oval, ápice agudo, base cuneada a arredondada.

4. Rhynchosia schomburgkii (Fig. 1, 2F-H, L, N) - Plântula CHR. Hipocótilo 1,5-2,5 x 1,2-1,5 mm, cilíndrico, glabro, branco. Epicótilo 45-82 x 1-1,2 mm, cilíndrico, verde-claro, densamente curto pubescentes, com tricomas glandulares pedunculados, juntamente com tricomas glandulares sésseis. Entrenó 1 9-30 mm compr., entrenó 2 10-19 mm compr. Estípulas do E1 1,9-2 x 0,4-0,5 mm, linear-lanceoladas, nos demais eofilos 1,8-2,2 x 0,5-0,6 mm, lanceoladas, 3-4-nervadas; folíolos com face adaxial esparsamente curto-pubescente, com tricomas simples e face abaxial esparsamente curto-pubescente, com tricomas simples e glandulares pedunculados, principalmente junto às nervuras, juntamente com tricomas glandulares sésseis. E1 1-foliolados, pecíolo 6-14 mm compr.; lâmina 15-28 x 15-24 mm, oval, ápice acuminado, base lobada; E2 1-foliolados, pecíolo 6-14 mm compr., lâmina 18-28 x 20-31 mm, oval, ápice acuminado, base truncada a arredondada; E3 1-foliolados, pecíolo 9-21 mm compr., lâmina 24-40 x 21-40 mm, oval, ápice acuminado, base truncada a arredondada.

\section{Chave de identificação de plântulas das espécies de Rhynchosia de Roraima, Brasil}

A diversidade de caracteres de plântulas permitiu a elaboração da seguinte chave de identificação de plântulas para as espécies estudadas, com dados até a expansão do eofilo de $3^{\circ}$ nó, enfatizando os caracteres úteis a partir do $1^{\circ}$ nó eofilar.

1. Plântula 1-foliolada pelo menos até o E3 (Fig. 2H) 4. R. schomburgkii

1. Plântula 1-foliolada somente no E1, subsequentemente 3-foliolada (Fig. 2A-E)

2. Folíolo do E1 com base truncada e ápice acuminado (Fig. 2I); estípulas dos E2 e E3 triangulares, 3-4-nervadas 1. $R$. phaseoloides

2. Folíolo do E1 com base lobada e ápice arredondado (Fig. 2J, K); estípulas dos E2 e E3 linear-lanceoladas, 1-nervadas 3. E1 com folíolo 18-24 mm larg. (Fig. 2B, C, J) e estípulas 2-3 mm compr.

3. E1 com folíolo 10-13 mm larg. (Fig. 2E, K) e estípulas 1-1,3 mm compr. 2. R. melanocarpa 3. R. minima

\section{Discussão}

Dentre as espécies estudadas, Rhynchosia schomburgkii e R. melanocarpa têm suas plântulas descritas pela primeira vez. Para R. phaseoloides e R. minima, os dados aqui apresentados ampliam o conhecimento disponível e esclarecem informações conflitantes na literatura para estas duas espécies.

Todas as quatro espécies ocorrentes em Roraima pertencem a Rhynchosia sect. Copisma Endlicher (Grear 1978). Dentro desta seção, $R$. schomburgkii é distinta das demais 28 espécies por apresentar o lobo inferior do cálice mais longo e estreito que os demais lobos, geralmente superando a corola em comprimento (Grear 1978). Como a distinção da espécie é sutil, é interessante destacar que, com relação à morfologia de plântulas, $R$. schomburgkii apresentou as plântulas mais idiossincráticas, pela ocorrência de eofilos 1-foliolados até o E3. Na literatura, todas as espécies estudadas de Rhynchosia apresentam, a partir do E2, folhas 3 -folioladas (Baudet 1974; Garwood 2009).

Para Rhynchosia phaseoloides, informações sobre seu tipo morfológico, pubescência do epicótilo, número e forma da base de folíolos e forma das estípulas do E1 foram apresentadas por Baudet (1974). Os resultados do presente trabalho concordam com os de Baudet (1974), com exceção da forma da base dos folíolos do E1. Baudet (1974) citou que $R$. phaseoloides apresenta E1 com base cordada, enquanto que todos os indivíduos desta espécie aqui observados possuem invariavelmente base truncada. Assim, ou R. phaseoloides pode ser considerada polimórfica quanto a este caráter, ou houve algum problema de identificação nos materiais analisados por Baudet (1974). Rhynchosia phaseoloides é, frequentemente, confundida com $R$. pyramidalis (Lam.) Urban ou com $R$. melanocarpa, sendo que esta última foi considerada como uma variedade de $R$. phaseoloides até o tratamento de Grear (1978), que a elevou ao nível específico. Considerando que o trabalho de Baudet (1974) é anterior à mudança taxonômica efetuada por Grear (1978), é possível que os espécimes de R. phaseoloides que Baudet (1974) examinou correspondam, de fato, à $R$. melanocarpa. Além disso, plântulas de espécimes roraimenses de $R$. melanocarpa apresentaram E1 com base lobada, variação que está mais próxima com a observada por Baudet (1974). De qualquer forma, considerando apenas as espécies de Roraima, a base truncada do E1 é um estado de caráter útil para distinguir os espécimes de R. phaseoloides das demais espécies ocorrentes no Estado, ressaltando-se que a observação de materiais de populações de outras regiões poderia esclarecer a plasticidade fenotípica dessas folhas.

Com relação à nictinastia, alguns trabalhos vêm demonstrando seu valor sistemático (Baudet 1974; Rodrigues \& Tozzi 2007a; 2008). Nas espécies estudadas, movimentos nictinásticos foram previamente citados somente para $R$. phaseoloides, e designados como "type A" por Baudet (1974). Estes movimentos correspondem à nictinastia descendente (Rodrigues \& Tozzi 2007a), que foi invariavelmente observada em todas as espécies aqui estudadas. 

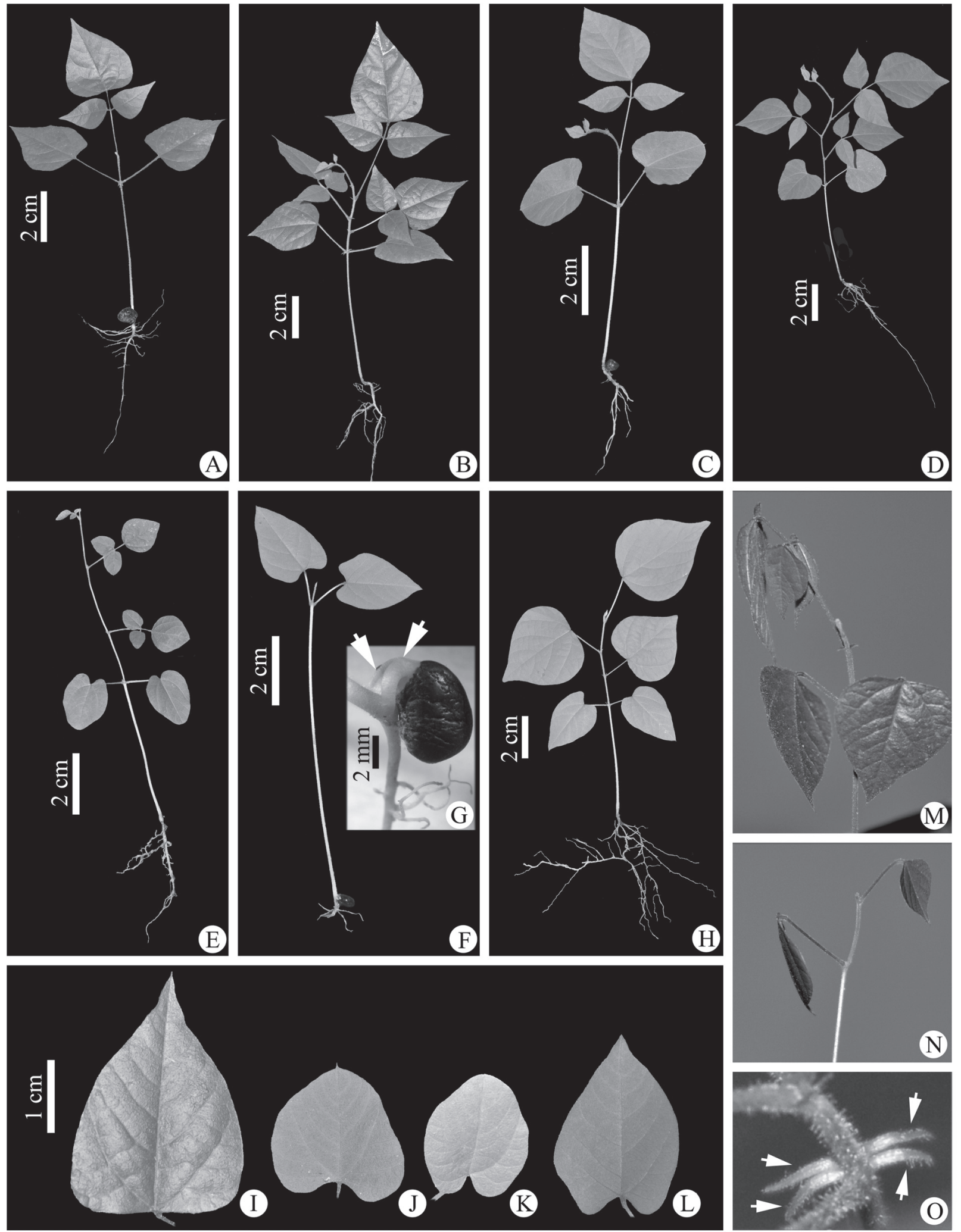

Figura 2. Plântulas de Rhynchosia Lour. (Leguminosae, Papilionoideae). A-B. Rhynchosia phaseoloides. C-D. Rhynchosia melanocarpa. E. Rhynchosia minima. F. Rhynchosia schomburgkii. G. Detalhe dos pecíolos cotiledonares (setas) de Rhynchosia schomburgkii. H. Rhynchosia schomburgkii. I-L. Eofilos do primeiro nó (E1). I. Rhynchosia phaseoloides. J. Rhynchosia melanocarpa. K. Rhynchosia minima. L. Rhynchosia schomburgkii. M-N. Nictinastia descendente. M. Rhynchosia phaseoloides. N. Rhynchosia schomburgkii. O. Estípulas duplas, livres entre si (setas), dos eofilos do primeiro nó de Rhynchosia phaseoloides. (A, M: Flores \& Rodrigues 2470; B, I, O: Flores \& Rodrigues 2475; C, J: Flores \& Rodrigues 2473; D: Flores \& Rodrigues 2477; E, K: Flores \& Rodrigues 2471; F, L: Flores \& Rodrigues 2478; G, N: Flores \& Rodrigues 2476; H: Flores \& Rodrigues 2479). 
Com o presente trabalho, e os dados de Baudet (1974) e Garwood (2009), existem dados de morfologia de plântulas para 10 espécies de Rhynchosia. Baudet (1974), em seu sumário de características em nível genérico em Phaseoleae, apontou que Rhynchosia apresenta exclusivamente plântulas hipógeas, E1 ("feuilles primordiales") com base não lobada ("non auriculée"), estípulas duplas, livres entre si, epicótilo pubescente, estipelas ausentes e E2 ("feuilles-1") 3-foliolados. Com a variação encontrada nas espécies em Roraima, é possível ampliar a descrição das características das plântulas de Rhynchosia: plântulas cripto-hipógeo-armazenadoras (CHR), E1 com base lobada, cordada ou truncada e estípulas duplas, livres entre si; epicótilo pubescente, com tricomas simples, eretos, canescentes, juntamente com tricomas glandulares sésseis, amarelos, eventualmente com tricomas glandulares pedunculados canescentes; estipelas ausentes até E3, com E2 e E3 1-3-foliolados.

Desta forma, citações de outros de grupos morfológicos, além do tipo CHR, podem ser consideradas problemáticas na literatura de Rhynchosia. Garwood (2009), em uma revisão dos tipos morfológicos de plântulas de táxons neotropicais, refere uma citação de uma espécie com plântula PER (CCC-CCR 2011) e outra com plântula PEF (Sanches \& Válio 2002). Imagens disponibilizadas em CCC-CCR (2011) de espécimes australianos de plântulas de R. minima foram interpretadas por Garwood (2009) como sendo PER. Além disso, CCC-CCR (2011) menciona que os cotilédones nesta espécie teriam uma nervura central profundamente endentada, conferindo-lhe uma forma em " $V$ ". Contudo, nossa interpretação é que houve provavelmente um problema de identificação, e que a plântula mais jovem apresentada em (CCC-CCR 2011) não corresponde ao gênero Rhynchosia. Isto se fundamenta na marcante diferença entre a forma da eofilos e do padrão de venação da plântula mais jovem em comparação com imagens apresentadas para plântulas mais desenvolvidas. Além disso, CCC-CCR (2011) menciona que os primeiros eofilos seriam 3-foliolados, o que, juntamente com cotilédones fanero-epígeos, não foram registrados em nenhuma espécie de Rhynchosia. Assim, de acordo com os dados aqui obtidos, $R$. minima possui somente plântulas CHR, o que está em conformidade com observações de Silcock (1980) para indivíduos australianos desta espécie.

No mesmo sentido, Sanches \& Válio (2002) referem plântulas PEF para Rhynchosia phaseoloides. Como discutido acima, informações relatadas por Baudet (1974) e no presente trabalho confirmam que esta espécie apresenta plântulas CHR. Assim, a interpretação mais provável é que Sanches \& Válio (2002) consideraram equivocadamente os primeiros eofilos como cotilédones, visto que esses também são opostos. Entretanto, testemunhas não foram citados por Sanches \& Válio (2002), como no caso acima relatado para R. minima, não sendo possível recuperar informações pela consulta a materiais de herbário.

Em conclusão, os resultados mostraram que a diversidade morfológica encontrada nas plântulas das espécies de Rhynchosia ocorrentes em Roraima permite identificá-las em nível específico. Além disso, foi documentada uma maior variação morfológica nas plântulas de Rhynchosia, principalmente com a descrição de plântulas exclusivamente 1-folioladas em $R$. schomburgkii. Desta forma, trabalhos desta natureza, descrevendo a variação de plântulas de diferentes táxons de Leguminosae, podem contribuir com a descoberta de caracteres taxonômicos relevantes adicionais, bem como auxiliar na identificação de táxons em estádios precoces de desenvolvimento, o que é especialmente importante em estudos de ecologia de plântulas.

\section{Agradecimentos}

Os autores agradecem à Fundação Estadual do Meio Ambiente, Ciência e Tecnologia de Roraima pelo apoio logístico para as coletas de material, a Gildo Vieira Feitoza pela ajuda na preparação do material em laboratório e ao assessor anônimo pelas valiosas sugestões à redação do manuscrito.

\section{Referências}

Baudet, J.C. 1974. Signification taxonomique des caracteres blastogèniques dans la tribu des Papilionaceae -Phaseoleae. Bulletin du jardin botanique national de Belgique 44: 259-293.

CCC-CCR (Cotton Catchment Communities-Cooperative Research Centres). 2011. Rhynco- Rhynchosia minima (L.) DC. Weed information and identification guide. http://www.cottoncrc.org.au/industry/ Publications/Weeds/Weed_IdentificationTools/Weedsby_common_ names/Ryncho (Acesso em 08/11/2011).

De Candolle, A.P. 1825. Mémoires sur la Famille des Légumineuses. Paris, A. Belin.

Duke, J.A. \& Polhill, R.M. 1981. Seedlings of Leguminosae. Pp. 941-949. In: Polhill, R.M.\& Raven, P.H. (Eds.). Advances in Legume Systematics. Part 2. Kew, Royal Botanic Gardens.

Garwood, N.C. 2009. Seedlings of Barro Colorado Island and the Neotropics. Ithaca, Comstock Publishing Associates.

Grear, J.W. 1978. A revision of the New World species of Rhynchosia (Leguminosae-Faboideae). Memoirs of the New York Botanical Garden 31: 1-168.

Hirt, A.P.M. \& Flores, A.S. 2012. O gênero Rhynchosia Lour. (LeguminosaePapilionoideae) no estado de Roraima, Brasil. Revista Brasileira de Biociências 10: 192-197.

Leck, M.A.; Parker, V.T. \& Simpson, R.L. 2008. Why seedlings? Pp. 3-13. In: Leck, M.A.; Parker, V.T. \& Simpson, R.L. (Eds.). Seedling Ecology and Evolution. Cambridge, Cambridge University Press.

Lima, H.C. 1990. Tribo Dalbergieae (Leguminosae Papilionoideae) - Morfologia dos frutos, sementes e plântulas e sua aplicação na sistemática. Arquivos do Jardim Botânico do Rio de Janeiro 30: 1-42.

López, J.; Devesa, J.A.; Ruiz, T. \& Ortega-Olivencia, A. 1998. Seedling morphology in Genisteae (Fabaceae) from south-west Spain. Botanical Journal of the Linnean Society 127: 229-250.

Lubbock, J. 1892. A contribution to our knowledge of seedlings. London, Kegan Paul, Trench, and Trüber. 2v.

Nemoto, T. \& Ohashi, H. 1993. Seedling morphology of Lespedeza (Leguminosae). Journal of Plant Research 106: 121-128.

Nozzolillo, C. 1977. Identification of Vicia seedlings. Canadian Journal of Botany 55: 2439-2462.

Nozzolillo, C. 1985. Seedling morphology and anatomy of eight Cicer species and their taxonomic value. Canadian Journal of Botany 63: 1-6. 
Oliveira, D.M.T. 2001. Morfologia comparada de plântulas e plantas jovens de leguminosas arbóreas nativas: espécies de Phaseoleae, Sophoreae, Swartzieae e Tephrosieae. Revista Brasileira de Botânica 24: 85-97.

Parra, P. 1984. Estudio de la morfologia externa de plântulas de Calliandra gracilis, Mimosa albida, Mimosa arenosa, Mimosa camporum y Mimosa tenuiflora. Revista de la Faculdad de Agronomia (Maracay) 13: $311-350$.

Rodrigues, R.S. \& Tozzi, A.M.G.A. 2007a. Morfologia de plântulas de cinco leguminosas genistóides arbóreas do Brasil (LeguminosaePapilionoideae). Acta Botanica Brasilica 21: 599-607.

Rodrigues, R.S. \& Tozzi, A.M.G.A. 2007b. Morfologia de plântulas no clado Vatairea (Leguminosae, Papilionoideae). Rodriguésia 58: 221-229.

Rodrigues, R.S. \& Tozzi, A.M.G.A. 2007c. Morphological analysis and re-examination of the taxonomic circumscription of Acosmium (Leguminosae, Papilionoideae, Sophoreae). Taxon 56: 439-452.
Rodrigues, R.S. \& Tozzi, A.M.G.A. 2008. Systematic relevance of seedling morphology in Acosmium, Guianodendron, and Leptolobium (Leguminosae, Papilionoideae). Brittonia 60: 287-296.

Sanches, M.C. \& Válio, I.F.M. 2002 Seed and seedling survival of some climber species in a southeast Brazilian tropical forest. Biotropica 34: 323-327.

Schrire, B.D. 2005. Phaseoleae Pp. 393-431. In: G. Lewis, Schrire, B., Mackinder, B. \& Lock, M. (eds.). Legumes of the World. Kew, Royal Botanic Gardens.

Silcock, R.G. 1980. Seedling characteristics of tropical pasture species and their implications for ease of establishment. Tropical Grasslands 14: $174-180$.

Thiers, B. 2012. Index Herbariorum: a global directory of public herbaria and associated staff. New York Botanical Garden's Virtual Herbarium. http://sweetgum.nybg.org/ih/ (Acesso em 20/04/2012).

Vogel, E.F. 1980. Seedlings of Dicotyledons. Wageningen, PUDOC. 